\title{
Maternal alcohol consumption may influence cord blood ascorbic acid concentration: findings from a study of Brazilian mothers and their newborns
}

\author{
Andréia Madruga de Oliveira*, Patrícia H. C. Rondó and Julicristie M. Oliveira \\ Department of Nutrition, Faculty of Public Health, University of São Paulo, Avenida Dr Arnaldo 715, \\ CEP-01246-904 São Paulo, SP, Brazil
}

(Received 4 June 2008 - Revised 25 February 2009 - Accepted 26 February 2009 - First published online 15 April 2009)

Studies that have investigated ascorbic acid (AA) concentrations in cord blood have pointed to significant associations with maternal blood AA concentrations, smoking, age, diet, type of delivery, duration of gestation, fetal distress and birth weight. The aim of the present study was to determine the relationship between cord blood AA concentrations in newborns and maternal characteristics. A total of 117 Brazilian healthy parturients were included in this cross-sectional study. The concentrations of AA in blood were determined by the HPLC method. Data concerning socio-economic, demographic, obstetric, nutritional and health characteristics of the parturients, including alcohol consumption and smoking habit, were assessed by a standardised questionnaire. A FFQ was used to investigate the intake of foods rich in vitamin C. Cord blood AA concentration was significantly correlated with per capita income $(r 0.26 ; P=0.005)$, maternal blood AA concentration $(r 0.48 ; P<0.001)$ and maternal vitamin C-rich food intake score $(r 0.36 ; P<0.001)$. The linear regression model including maternal AA concentration, alcohol consumption, smoking, parity, vitamin C-rich food intake score and per capita income explained $31.13 \%$ of the variation in cord blood AA concentrations in newborns. We recommend further experimental studies to assess the effects of ethanol on placental AA uptake, and epidemiological cohort studies to evaluate in detail the influence of maternal alcohol consumption on cord blood AA concentrations.

Ascorbic acid: Ascorbic acid deficiency: Newborns: Income: Alcohol: Parity

Vitamin $\mathrm{C}$ is an essential water-soluble micronutrient required for multiple biological functions. This vitamin is a cofactor of several enzymes, promotes Fe absorption, and has antiscorbutic and antioxidant actions ${ }^{(1)}$.

Few studies have assessed the prevalence of vitamin $\mathrm{C}$ deficiency or blood ascorbic acid (AA) concentrations in infants or newborns. Villalpando et al. ${ }^{(2)}$ investigated the prevalence of vitamin $\mathrm{C}$ deficiency in Mexican infants (aged 0-2 years) using the data from the 1999 National Nutrition Survey. The prevalence of vitamin $\mathrm{C}$ deficiency $(\leq 2 \mathrm{mg} / \mathrm{l}$ or $\leq 11.4 \mu \mathrm{mol} / \mathrm{l}$ ) in this group was $30.3 \%$ and the mean blood AA concentration was $4 \mathrm{mg} / \mathrm{l}(22.8 \mu \mathrm{mol} / \mathrm{l})$. Studies that assessed AA concentrations in cord blood reported means of $78.6(\mathrm{SD} 5 \cdot 2) \mu \mathrm{mol} / \mathrm{l}$ in newborns of low socio-economic status from $\mathrm{USA}^{(3)}, 92 \cdot 11(95 \%$ CI $88.94,95 \cdot 29) \mu \mathrm{mol} / 1$ in British newborns ${ }^{(4)}$ and 172.9 (SD 39.2) $\mu \mathrm{mol} / 1$ in newborns from Israel ${ }^{(5)}$.

Studies that investigated AA concentrations in cord blood pointed to significant associations with maternal blood AA concentrations $^{(3,4,6-9)}$, smoking ${ }^{(9-11)}$ age $^{(6)}$, diet $^{(4)}$, type of delivery $^{(4,12)}$, duration of gestation ${ }^{(13,14)}$, fetal distress ${ }^{(5)}$ and birth weight ${ }^{(3,14)}$. According to Scaife et al. ${ }^{(4)}$ vitamin C intake in pregnancy is significantly correlated with maternal ( $r 0.17 ; P<0 \cdot 001)$ and cord blood $(r 0 \cdot 10 ; P=0.01)$ AA concentrations at delivery. Although there is no study assessing the relationship between alcohol consumption during pregnancy and blood AA concentrations, previous studies have shown an association between alcohol and AA status in humans ${ }^{(15,16)}$. As far as we know, there are no studies assessing vitamin $\mathrm{C}$ status in Brazilian newborns. We hypothesised that cord blood AA concentrations could be influenced by maternal socio-economic, demographic, obstetric, nutritional and health factors. Therefore, the aim of the present study was to determine the relationship between cord blood AA concentrations in newborns and maternal characteristics, including alcohol consumption.

\section{Experimental methods}

The methods have been described elsewhere ${ }^{(17)}$. A total of 117 healthy parturients admitted from October to December 2002 at the Obstetric Centre of Hospital Universitário (University of São Paulo, Brazil) were included in this cross-sectional study. Women with a history of infectious diseases, metabolic disorders, pre-eclampsia/eclampsia, twin-pregnancies, with a gestational age $<37$ and $\geq 42$ weeks, and those who gave birth to an infant with a weight $<2500$ g were excluded.

Data concerning socio-economic, demographic, obstetric, nutritional and health characteristics of the parturients,

Abbreviation: AA, ascorbic acid.

* Corresponding author: Andréia Madruga de Oliveira, fax +113061 7771, email andmo@usp.br 
including alcohol consumption and smoking habit, were assessed by a standardised questionnaire.

The parturients were asked about the amount, frequency and type of alcoholic beverage ingested in pregnancy. Smoking was estimated by the mean number of cigarettes smoked per d throughout pregnancy.

A retrospective FFQ was used to determine the maternal consumption of twenty-two Brazilian foods rich in vitamin C. The questionnaire was adapted from a study carried out by Fornés et al. ${ }^{(18)}$, but not validated for vitamin $\mathrm{C}$. The method was modified using five different scores: 0 , never; $0 \cdot 07$, one to three times per month; $0 \cdot 28$, once to three times per week; $0 \cdot 71$, four to six times per week; 1 , once per $\mathrm{d}$. A single vitamin $\mathrm{C}$-rich food intake score was obtained adding the different scores for each food. The level and bioavailability of vitamin $\mathrm{C}$ in each food were not considered. Cord blood $(6 \mathrm{ml})$ and maternal blood $(4 \mathrm{ml})$ were centrifuged, and the plasma immediately stored in a $-80^{\circ} \mathrm{C}$ freezer, for a maximum of $4 \mathrm{~d}$, until determination of vitamin $\mathrm{C}$ by HPLC, using the method of Wayner \& Burton ${ }^{(19)}$.

The differences between mean cord blood AA, maternal blood AA concentrations, per capita income, and vitamin C-rich food intake score by type of delivery, parity, alcohol consumption and use of supplements containing vitamin C (in combination with other nutrients) were assessed by the Mann-Whitney test. The $\chi^{2}$ test was used to assess the association between the categorical variables smoking and alcohol consumption. Cord and maternal blood AA concentrations, per capita income, and vitamin C-rich food intake score were converted to natural $\operatorname{logs}$, because they did not have normal distribution. The correlations between cord blood AA concentrations, per capita income, maternal vitamin C-rich food intake score and maternal blood AA concentrations were obtained by the Pearson's correlation coefficient. Multiple linear regression models were used to determine the relationship between cord blood AA (dependent variable) and maternal blood AA concentrations, vitamin C-rich food intake score, alcohol consumption, smoking and parity (independent variables). A forward selection process was used in which the independent variables and confounders were added to the model. Analysis of the residuals of the final model showed homogeneity and no bias. The differences were considered statistically significant when $P<0 \cdot 05$. Data were analysed in Stata software (Statistical Software for Professionals, release 8, 2005; StataCorp LP, College Station, TX, USA).

The present study was conducted according to the guidelines laid down in the Declaration of Helsinki and all procedures involving human subjects and patients were approved by the Research Ethics Committees of the Faculty of Public Health and Hospital Universitário. Written informed consent was obtained from all subjects and patients.

\section{Results}

Most of the infants $(88.0 \%)$ had a gestational age between 39 and 41 weeks and $95.7 \%$ were born with a weight of 2500-4000 g. The mean cord blood AA concentration was $92.03(95 \%$ CI 84.61, 99.46) $\mu \mathrm{mol} / 1$, and $62.4 \%$ of the newborns had concentrations $<100 \mu \mathrm{mol} / \mathrm{l}$. Almost $70 \%$ of the parturients had a vaginal delivery $(51.3 \%$ normal and $18.8 \%$ forceps). The prevalence of maternal vitamin $\mathrm{C}$ deficiency $(<22.7 \mu \mathrm{mol} / \mathrm{l})$ was $30.8 \%$, and mean maternal blood AA concentration was 33.42 (95\% CI 30.15, 36.69) $\mu \mathrm{mol} / \mathrm{l}$. Almost $90 \%$ of the women had a vitamin C-rich food intake score varying from 0.5 to 6.0 , and thirty $(25.64 \%)$ smoked during pregnancy. From the twenty-one parturients who consumed alcohol in pregnancy, sixteen (76\%) of them ingested beer, of which eleven of them ingested less than $300 \mathrm{ml} \mathrm{a}$ time, and five of them from $400-600 \mathrm{ml}$ a time. Five $(24 \%)$ of the parturients ingested wine, from 100 to $400 \mathrm{ml}$ a time. Both groups of women ingested alcoholic beverages only socially, less than seven times per month, throughout pregnancy. Thirty parturients smoked cigarettes in pregnancy, of which eleven smoked less than six cigarettes per d, eleven smoked from seven to ten cigarettes per $\mathrm{d}$, and eight smoked more than ten cigarettes per d.

Approximately $48 \%$ of the parturients were primiparous and $79.5 \%$ of them had a low economic status, with a per capita income below one minimum Brazilian wage (US\$ 187.27).

There were no significant differences between mean AA concentrations in cord blood of newborns according to type of delivery and use of supplements. However, mean AA concentration was statistically higher in cord blood of newborns of primiparous than multiparous women. Maternal alcohol consumption was also associated with cord blood AA concentrations. Newborns whose mothers consumed alcohol during gestation had significantly lower concentrations of AA in cord blood at delivery compared with newborns whose mothers denied alcohol consumption (Table 1).

Cord blood AA concentration was significantly correlated with per capita income $(r 0.26 ; P=0.005)$, maternal blood AA concentration $(r 0.48 ; P<0.001)$ and maternal vitamin C-rich food intake score $(r 0.36 ; P<0.001)$. Cord blood AA and maternal AA concentrations ratios were 2.89 (SD 1.51) and 3.16 (SD 1.39) for those women who consumed, and did not consume alcohol in pregnancy, respectively.

Alcohol consumption was strongly associated with smoking habit $\left(\chi^{2} 6.48 ; P=0 \cdot 01\right)$. Therefore, we included smoking in the multiple linear regression analyses as a controlling variable. Even after this adjustment, alcohol consumption was still significantly associated with cord blood AA concentration. The linear regression model including maternal AA concentration, alcohol consumption, smoking, parity, vitamin C-rich food intake score and per capita income explained $31.13 \%$ of the variation in cord blood AA concentrations in newborns (Table 2).

\section{Discussion}

In the present study, cord blood AA concentration was not associated with type of delivery and use of supplements, but it was associated with parity, maternal blood AA concentration, per capita income, vitamin C-rich food intake score and maternal alcohol consumption.

The mean cord blood AA in Brazilian newborns $(92 \mu \mathrm{mol} / \mathrm{l})$ was similar to that described in British newborns $(92.11$ $\mu \mathrm{mol} / \mathrm{l})^{(4)}$, but was lower than the mean reported by Dvir et al. ${ }^{(5)}$ for newborns from Israel $(172.9 \mu \mathrm{mol} / \mathrm{l})$.

Woods et al. ${ }^{(12)}$ and Scaife et al. ${ }^{(4)}$ described significant differences in mean cord blood AA concentrations of 
Table 1. Cord blood ascorbic acid (AA) concentration, per capita income, maternal blood AA and vitamin C-rich food intake score according to type of delivery, parity, alcohol consumption and use of supplements containing vitamin $\mathrm{C}$

(Mean values and standard deviations for 117 subjects)

\begin{tabular}{|c|c|c|c|c|c|c|c|c|}
\hline & \multicolumn{2}{|c|}{$\begin{array}{l}\text { AA in cord blood } \\
(\mu \mathrm{mol} / /)\end{array}$} & \multicolumn{2}{|c|}{ Per capita income* } & \multicolumn{2}{|c|}{$\begin{array}{l}\text { AA in maternal } \\
\text { serum }(\mu \mathrm{mol} / \mathrm{l})\end{array}$} & \multicolumn{2}{|c|}{$\begin{array}{l}\text { Vitamin C-rich food } \\
\text { intake score } †\end{array}$} \\
\hline & Mean & SD & Mean & SD & Mean & SD & Mean & SD \\
\hline \multicolumn{9}{|l|}{ Type of delivery } \\
\hline Vaginal ( $n$ 82) & $90 \cdot 9$ & $41 \cdot 0$ & 0.81 & 0.89 & 33.6 & $18 \cdot 9$ & 3.6 & $2 \cdot 0$ \\
\hline Caesarean section $(n 35)$ & 94.6 & $40 \cdot 0$ & 0.78 & 0.64 & 32.9 & $15 \cdot 2$ & 3.9 & 1.5 \\
\hline$P$ & \multicolumn{2}{|c|}{0.917} & \multicolumn{2}{|c|}{0.677} & \multicolumn{2}{|c|}{0.943} & \multicolumn{2}{|c|}{0.274} \\
\hline \multicolumn{9}{|l|}{ Parity } \\
\hline Primiparous ( $n 56$ ) & $100 \cdot 3$ & $37 \cdot 8$ & 0.94 & 0.89 & 34.4 & $16 \cdot 1$ & 3.7 & 1.7 \\
\hline Multiparous ( $n$ 61) & 84.4 & 41.9 & 0.67 & 0.74 & 32.5 & $19 \cdot 4$ & 3.7 & $2 \cdot 0$ \\
\hline$P$ & \multicolumn{2}{|c|}{0.020} & \multicolumn{2}{|c|}{0.021} & \multicolumn{2}{|c|}{0.384} & \multicolumn{2}{|c|}{0.933} \\
\hline \multicolumn{9}{|l|}{ Alcohol consumption } \\
\hline Yes $(n 21)$ & $73 \cdot 1$ & $34 \cdot 6$ & 0.69 & 0.49 & 29.5 & $15 \cdot 8$ & $4 \cdot 1$ & $2 \cdot 0$ \\
\hline No ( $n$ 96) & $96 \cdot 2$ & $40 \cdot 8$ & 0.83 & 0.88 & $34 \cdot 2$ & $18 \cdot 2$ & 3.6 & $1 \cdot 8$ \\
\hline$P$ & \multicolumn{2}{|c|}{0.044} & \multicolumn{2}{|c|}{0.647} & \multicolumn{2}{|c|}{0.265} & \multicolumn{2}{|c|}{0.226} \\
\hline \multicolumn{9}{|c|}{ Use of supplements containing vitamin C } \\
\hline Yes $(n 27)$ & $99 \cdot 1$ & 34.4 & 1.02 & 1.07 & 35.5 & 12.5 & 4.0 & $2 \cdot 2$ \\
\hline No $(n 90)$ & 89.9 & $42 \cdot 2$ & 0.74 & 0.73 & $32 \cdot 8$ & $19 \cdot 2$ & 3.6 & 1.7 \\
\hline$P$ & \multicolumn{2}{|c|}{0.223} & \multicolumn{2}{|c|}{0.156} & \multicolumn{2}{|c|}{0.128} & \multicolumn{2}{|c|}{0.598} \\
\hline Total $(n 117)$ & $92 \cdot 0$ & $40 \cdot 6$ & 0.80 & 0.82 & 33.4 & $17 \cdot 9$ & 3.7 & 1.8 \\
\hline
\end{tabular}

* Given as a proportion of the Brazilian minimum wage (US\$ 187.27).

†For calculation of the vitamin C-rich food intake score, see the Experimental methods section.

newborns whose mothers laboured and did not labour at delivery. According to Woods et al. ${ }^{(12)}$, uterine contractile activity may generate reactive oxidative species that can lead to a significant depletion of vitamin $\mathrm{C}$ during labour. Maternal intake of supplements containing vitamin $\mathrm{C}$ during pregnancy did not influence mean cord blood AA concentration. Dejmek et al. ${ }^{(9)}$ compared mean cord blood AA concentrations between mothers who used and did not use supplements containing vitamin $\mathrm{C}$ during pregnancy. Supplementation showed a beneficial effect only for smoking mothers.

Vobecky et al. ${ }^{(6)}$ assessed the relationship between cord blood AA concentrations and parity, but did not describe any significant difference. In the present study, mean cord blood AA concentration was higher in primiparous than in multiparous women.

The positive correlation between maternal blood AA and cord blood AA concentrations is well described in the literature $^{(3,4,6-9)}$. Few studies assessed maternal dietary vitamin $\mathrm{C}$

Table 2. Multivariate linear regression models including ascorbic acid (AA) concentration in the cord blood of newborns as the dependent variable* ( $\beta$ Coefficients with their standard errors for 117 subjects)

\begin{tabular}{lrcc}
\hline Variables & $\beta$ & SE & $P$ \\
\hline Maternal AA concentration & 0.39 & 0.11 & 0.001 \\
Vitamin C-rich food intake score $†$ & 0.19 & 0.11 & 0.084 \\
Alcohol consumption $\ddagger$ & -0.46 & 0.13 & 0.001 \\
Smoking $\ddagger$ & 0.12 & 0.12 & 0.314 \\
Parity & -0.22 & 0.10 & 0.033 \\
Per capita income & 0.03 & 0.07 & 0.647 \\
\hline
\end{tabular}

${ }^{*}$ Adjusted $R^{2} 0.3113(P<0.001)$.

†For calculation of the vitamin C-rich food intake score, see the Experimental methods section.

$\ddagger$ Yes $=1 ;$ no $=0$. intake $^{(4,12)}$, and only Scaife et al. ${ }^{(4)}$ described a significant correlation between vitamin $\mathrm{C}$ in the diet and cord blood AA concentration.

Alcohol consumption was significantly associated with cord blood AA concentration. However, mean maternal blood AA concentration was not significantly different in mothers who reported (29.5 (SD 15.8) $\mu \mathrm{mol} / \mathrm{l})$ and did not report alcohol consumption (34.3 (SD 18.2) $\mu \mathrm{mol} / \mathrm{l})$ during pregnancy $(P=0 \cdot 268)$.

As far as we know there is no study in the literature assessing the influence of maternal alcohol consumption on cord blood AA concentrations. We hypothesise that alcohol consumption can impair vitamin $\mathrm{C}$ transport through the placenta and/or enhance oxidative stress to the fetus, thus, increasing antioxidant requirements.

According to Burd et al. ${ }^{(20)}$, prenatal alcohol exposure may play an important role in abnormalities of placental function and development. Alcohol produces placental vasoconstriction that may impair blood flow, and consequently nutrient transport. It can also induce oxidative stress in the placenta and possibly produces spasm in umbilical cord veins and arteries. Moreover, alcohol consumption can reduce placental weight, and increase villous infarction and intervillous thrombi.

Although Burd et al. ${ }^{(20)}$ pointed out that maternal alcohol consumption is enhanced in poor populations and with inadequate diet, we found no differences regarding per capita income or vitamin C-rich food intake score between women who consumed or did not consume alcohol during pregnancy.

We recommend the development of experimental studies assessing the placental transport of ethanol and its impact on AA uptake. It is also important to carry out further epidemiological cohort studies to evaluate, in detail, the association between alcohol consumption in pregnancy and cord blood 
AA concentrations in newborns, controlling for ingestion of vitamin C-rich foods, smoking and socio-economic status.

\section{Acknowledgements}

The authors would like to extend their thanks to Conselho Nacional de Desenvolvimento Científico e Tecnológico (National Council for Scientific and Technological Development) for supporting the Master's degree scholarship of A. M. de O. This research received no specific grant from any funding agency in the public, commercial or not-forprofit sectors.

A. M. de O. designed the study protocol, collected the data and wrote the paper. P. H. C. R. designed the study protocol, interpreted the results and wrote the paper. J. M. O. performed the statistical analysis, interpreted the results and wrote the paper.

There are no conflicts of interest.

\section{References}

1. Duarte TL \& Lunec J (2005) Review: when is an antioxidant not an antioxidant? A review of novel actions and reactions of vitamin C. Free Radic Res 39, 671-686.

2. Villalpando S, Montalvo-Velarde I, Zambrano N, et al. (2003) Vitamins $\mathrm{A}$, and $\mathrm{C}$ and folate status in Mexican children under 12 years and women $12-49$ years: a probabilistic national survey. Salud Publica Mex 4, 508S-519S.

3. Jain SK, Wise R, Yanamandra K, et al. (2008) The effect of maternal and cord-blood vitamin $\mathrm{C}$, vitamin $\mathrm{E}$ and lipid peroxide levels on newborn birth weight. Mol Cell Biochem 309, 217-221.

4. Scaife AR, McNeill G, Campbell DM, et al. (2006) Maternal intake of antioxidant vitamins in pregnancy in relation to maternal and fetal plasma levels at delivery. Br J Nutr 95, $771-778$.

5. Dvir M, Kohelet D, Arbel E, et al. (1992) Umbilical ascorbic acid levels in fetal distress. J Nutr Sci Vitaminol (Tokyo) 38 $511-515$

6. Vobecky JS, Vobecky J, Shapcott D, et al. (1982) Biochemical indices of nutritional status in maternal, cord, and early neonatal blood. Am J Clin Nutr 36, 630-642.
7. Heinz-Erian P, Achmüller M, Berger H, et al. (1987) Vitamin C concentrations in maternal plasma, amniotic fluid, umbilical cord blood, the plasma of newborn infants, colostrum and transitory and mature breast milk. Padiatr Padol 22, 163-178.

8. Dziaman T, Gackowski D, Rozalski R, et al. (2007) Urinary excretion rates of 8-oxoGua and 8-oxodG and antioxidant vitamins level as a measure of oxidative status in healthy, full-term newborns. Free Radic Res 41, 997-1004.

9. Dejmek J, Ginter E, Solanský I, et al. (2002) Vitamin C, E and A levels in maternal and fetal blood for Czech and Gypsy ethnic groups in the Czech Republic. Int J Vitam Nutr Res 72, $183-190$.

10. Ortega RM, López-Sobaler AM, Quintas ME, et al. (1998) The influence of smoking on vitamin $\mathrm{C}$ status during the third trimester of pregnancy and on vitamin C levels in maternal milk. $J$ Am Coll Nutr 17, 379-384.

11. Madruga de Oliveira A, Rondó PH \& Barros SB (2004) Concentrations of ascorbic acid in the plasma of pregnant smokers and nonsmokers and their newborns. Int J Vitam Nutr Res 74, 193-198.

12. Woods JR Jr, Cavanaugh JL, Norkus EP, et al. (2002) The effect of labor on maternal and fetal vitamins C and E. Am J Obstet Gynecol 187, 1179-1183.

13. Guajardo L, Beharry KD, Modanlou HD, et al. (1995) Ascorbic acid concentrations in umbilical cord veins and arteries of preterm and term newborns. Biol Neonate 68, 1-9.

14. Baydas G, Karatas F, Gursu MF, et al. (2002) Antioxidant vitamin levels in term and preterm infants and their relation to maternal vitamin status. Arch Med Res 33, 276-280.

15. Bonjour JP (1979) Vitamins and alcoholism. I. Ascorbic acid. Int J Vitam Nutr Res 49, 434-441.

16. Fazio V, Flint DM \& Wahlqvist ML (1981) Acute effects of alcohol on plasma ascorbic acid in healthy subjects. Am J Clin Nutr 34, 2394-2396.

17. Madruga de Oliveira A, Rondó PH, Mastroeni SS, et al. (2008) Plasma concentrations of ascorbic acid in parturients from a hospital in Southeast Brazil. Clin Nutr 27, 228-232.

18. Fórnes NS, Martins IS, Herman M, et al. (2000) Food frequency consumption and lipoproteins serum levels in the population of an urban area, Brazil. Rev Saúde Publ 34, 380-387.

19. Wayner DMM \& Burton GV (1989) Measurement of individual and radical trapping activity. In Handbook of Free Radicals and Antioxidants in Biomedicine, pp. 223-232 [J Miguel, A Quintanilha and $\mathrm{H}$ Weber, editors]. Boca Raton, FL: CRC Press.

20. Burd L, Roberts D, Olson M, et al. (2007) Ethanol and the placenta: a review. J Matern Fetal Neonatal Med 5, 361-375. 